NASA-CR-204623

\title{
Assessment of Rainfall Estimates Using a Standard $Z-R$ Relationship and the Probability Matching Method Applied to Composite Radar Data in Central Florida
}

\author{
WiLliam L. Crosson \\ Institute for Giobal Change Research and Education, * Huntsville. Alabama \\ Claude E. Duchon \\ School of Meteorology, University of Oklahoma, Norman, Oklahoma \\ RAVIKUMAR RAGHAVAN \\ Institute for Global Change Research and Education, Huntsville, Alabama \\ STEven J. GoODMAN \\ NASA/Marshall Space Flight Center, Hantsville, Alabama
}

(Manuscript received 17 October 1994, in final form 30 October 1995)

\section{ABSTRACT}

\begin{abstract}
Precipitation estimates from radar systems are a crucial component of many hydrometeorological applications. from flash flood forecasting to regional water budget studies. For analyses on large spatial scales and long from flash flood forecasting to regional water budget studies. For analyses on large spatial scales a remstems. Such composite products are useful for regional or national studies, but introduce a set of difficulties not encountered when using single radars. For instance, each contributing radar has its own calibration and scanning characteristics, but radar identification may not be retained in the compositing procedure. As a result, range effects on signal return cannot be taken into account.

This paper assesses the accuracy with which composite radar imagery can be used to estimate precipitation in the convective environment of Florida during the summer of 1991 . Results using $Z=300 R^{\mathrm{i} / 4}$ (WSR-88D in the convective environment of Florida during the summer of 1991 . Results using $Z$. Rainfall derived from the power law $Z-R$ was found to be highly biased $(+90 \%-110 \%)$ compared to rain Rainfall derived from the power law $Z-R$ was found to be highly biased $(+90)$ a old (determined via the PMM) was found to improve the performance of the power law $Z-R$, reducing the (d) Correlations between precipitation estimates obtained with either $Z-R$ relabiases substantially to $20 \%-33 \%$. Correlations between precipitation estimates obtained with either $Z-R$ relationship and mean gauge values are much higher for areal averages than for point locations. Precipitation estimates from the PMM are an improvement over those obtained using the power law in that biases and rootmean-square errors are much lower. The minimum timescale for application of the PMM with the composite radar dataset was found to be several days for area-average precipitation. The minimum spatial scale is harder to quantify, although it is concluded that it is less than $350 \mathrm{~km}^{2}$. Implications relevant to the WSR-88D system are discussed.
\end{abstract}

\section{Introduction}

a. Motivation and objectives

Meteorological radars have been used since the 1940s to estimate rainfall. Most efforts have focused

* IGCRE is jointly operated by the University of Alabama in Huntsville and the Universities Space Research Association.

Corresponding author address: Dr. William L. Crosson, Global Hydrology and Climate Center, 977 Explorer Blvd.. Huntsville, AL 35806 .

E-mail: hill.crosson (a) msfic.nasa.gov on short time and/or small spatial scales due to data availability, range-height sampling considerations, and processing limitations. However, there are many hydrologic and surface energy flux modeling applications that require the rain field to be estimated on larger spatial and longer temporal scales. Measurement and modeling efforts to determine surface water and energy fluxes require precipitation estimates, either from in situ (rain gauge) measurements, remote (radar) observations, or a combination of both. Validation of atmospheric models from the mesoscale to the global scale also depends on accurate measurement-based area-average precipitation estimates. There is a crucial need in these applications for unbiased estimates, a re- 
sult that cannot be guaranteed when conventional $Z-R$ relationships are used.

An example of a large-scale hydrologic and energy cycle study in which precipitation plays a major role is the GEWEX (Global Energy and Water Cycle Experiment) Continental-Scale International Project (GCIP), to be conducted over the Mississippi River basin between 1995 and 1999 (Leese 1993). As part of GCIP, precipitation data derived from rain gauges and radars will be needed for initializing, driving, and validating coupled hydrologic-atmospheric models, with the purpose of examining the space-time variability of water and energy budgets up to the continental scale. The GCIP precipitation requirement is hourly rainfall at $4-\mathrm{km}$ horizontal resolution over the entire Mississippi basin (Leese 1993). In addition. space missions such as NASA's Tropical Rainfall Measuring Mission (TRMM; see Simpson et al. 1988) designed to estimate global rainfall also depend on reliable radarrainfall measurements for validation purposes.

In this paper we present results obtained by applying the probability matching method (PMM) - as described by Calheiros and Zawadzki (1987), Atlas et al. (1990b) and Rosenfeld et al. (1993) - to rain gauge and radar data collected in central Florida during the summer of 1991. Radar and rain gauge datasets are described in section 2. Rainfall estimates obtained using this technique are compared with results obtained from the $Z-R$ relation $Z=300 R^{1.4}$. This relationship was developed for convective rainfall during the Florida Area Cumulus Experiment (FACE; see Woodley et al. 1975 ) and, therefore, should be appropriate for central Florida. The FACE $Z-R$ is also the default WSR$88 \mathrm{D}$ algorithm.

As will be shown in section 3, application of the FACE $Z-R$ relationship to "NOWRAD" composite radar reflectivity images produced by the WSI Corporation resulted in large systematic and random errors in radar-estimated rainfall, with respect to rain gauge values. These results suggested a need for alternative techniques that are more appropriate for use with composite reflectivity data. The current study provides an initial test of the PMM applied to a composite radar product, a type of data that is currently being used for precipitation estimation. Although the composite radar dataset used in this study is suboptimal in that it was obtained from WSR-57 systems, the analysis presented here has implications for potential application of the PMM technique to produce regional and national rainfall maps based on composite radar imagery. The data currently used to create national precipitation map products comprise reflectivities from WSR-57, WSR74 , and WSR-88D radars and are archived as part of EOSDIS (Earth Observing System Data and Information System) at the Hydrology DAAC (Distributed Active Archive Center) at the Marshall Space Flight Center. The national composite precipitation product provides coverage at an $8-\mathrm{km}$ grid spacing, averaged from the original $2-\mathrm{km}$ reflectivity data. Unfortunately, individual radar identification is lost in the compositing procedure, so that, in general, range effects on signal return cannot be taken into account. Nevertheless, this type of composite radar data represents the only feasible radar product for regional or continental-scale meteorological and hydrologic studies.

This paper focuses on the assessment of PMM rainfall estimates over a range of space and time domains compared with results obtained using the conventional FACE relationship. In so doing, a strategy is defined that may be used with WSR-88D systems, which should yield better results due to enhanced radar characteristics. Results obtained herein provide a baseline against which future results may be compared.

Estimation of rainfall from gauge networks and from radars each has its own advantages and disadvantages. Because rain galuges provide point measurements, the accuracy of estimating area-average rainfall from gauges is dependent on the area, the number of gauges and correlation structure of the rainfield, as well as measurement errors. Duchon et al. (1995) applied spatial sampling theory to quantify systematic and random errors associated with estimating daily area-average rainfall from the rain gauge network. Radar provides much better spatial coverage and often captures isolated storms that go undetected by rain gauges. Radar estimation of rainfall is hampered by uncertainties in converting reflectivities to rain rates through a $Z-R$ relationship, a procedure that is fraught with difficulties involving radar calibration as well as environmental conditions such as precipitation type and phase (convective vs stratiform, liquid vs solid), local biases due to various radar types, anomalous propagation, and range effects.

This study utilizes data from the Convection and Precipitation/Electrification Experiment (CaPE) conducted in central Florida during the period 8 July -18 August 1991 (Williams et al. 1992). CaPE provided an excellent dataset of meteorological and hydrologic measurements and thus the opportunity to compare radar-and rain gauge-based rainfall estimates. Figure 1 shows the distribution of rain gauges within and around the study domain. which contains over 200 rain gauges and covers approximately $21000 \mathrm{~km}^{2}$, as well as the Merritt Island rain gauge cluster area, which encompasses approximately $350 \mathrm{~km}^{2}$ and 21 gauges. Hydrometeorological applications such as flash flood forecasting and land surface process modeling require precipitation estimates at time steps of $1-12 \mathrm{~h}$, motivating an assessment of hourly to daily precipitation estimates using radars and gauges. It is clear from Fig. 1 that, in the presence of highly variable convective rainfall over the study area during the Florida summer season, estimation of hourly precipitation is problematic given the distribution of 1 -min and hourly recording gauges. Thus, radar becomes an essential measurement tool since it provides nearly continuous spatial and temporal 


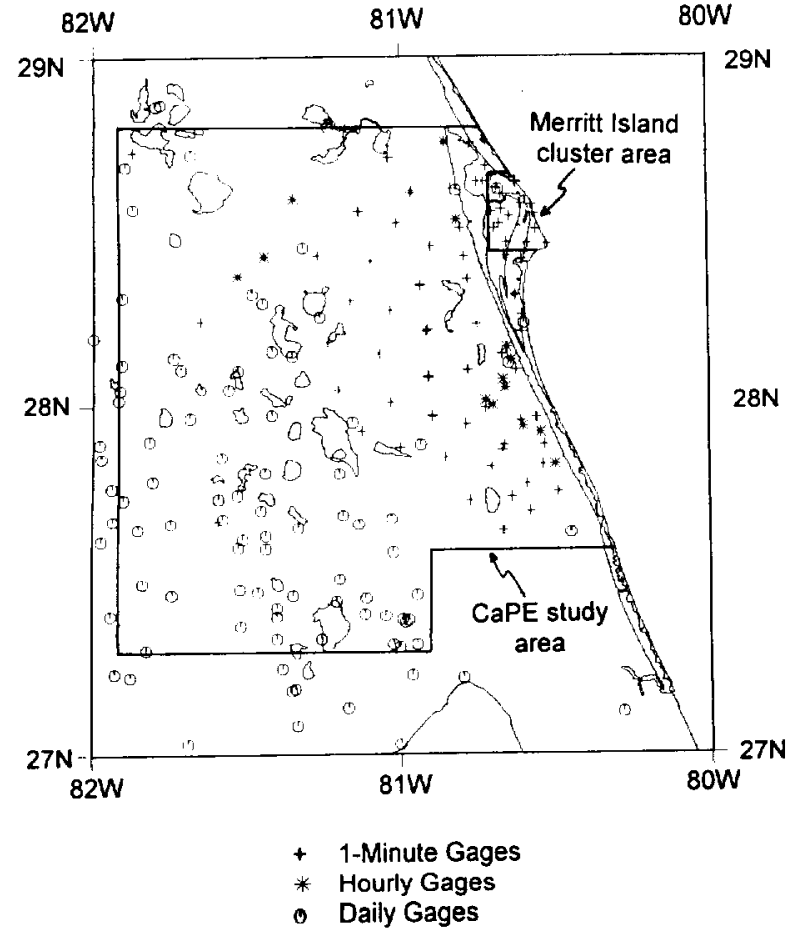

FiG. 1. Map of the CaPE study area with locations of 1-min, hourly and daily rain gauges. The CaPE study area and Merritt Island rain gauge cluster area are outlined.

coverage over the entire experimental space-time domain.

The two specific objectives addressed in this paper are:

1) Utilize composite radar data, in conjunction with the rain gauge network, to obtain a "climatologically tuned" $Z-R$ relation for central Florida, following the PMM approach. In this context, a "climatologically tuned" ' $Z-R$ relation is one that is developed by matching observed probability density functions (PDFs) of radar reflectivities and gauge-measured rain rates. Implementation of the PMM using CaPE data is discussed in section 4 .

2) Apply both the PMM and FACE $Z-R$ relations to estimate rainfall over a range of space-time domains, compare the results, and assess the associated errors. An underlying assumption is that a PMM-derived $Z-R$ relationship is valid only for space-time domains large enough to capture a number of rain systems at various stages of their life cycles. This is because physical and microphysical characteristics change as rain systems, especially convective ones, evolve from the nascent to mature stages. Thus, the question that arises is: On what spatial and temporal scales is the application of such a relation valid? This question will be addressed by comparing gauge- and radar-estimated rainfall over a wide range of scales- from hourly rainfall at point locations to spatial averages for the CaPE study area over a 14-day period.

Accuracy of radar-derived rainfall estimates has been evaluated relative to rain gauge measurements from the gauge networks within the study area and the smaller, more densely gaged Merritt Island region. There are several sources of error, both random and nonrandom, in the gauge data. These include wind effects, hardware, and electronic errors, and errors associated with the extension of point measurements to area-average rainfall (Willmott and Legates 1991). The gauge data used here received extensive quality assessment as will be described in section 2. Rainfall based on the gauge measurements after application of these quality control measures is considered to be "ground truth" in these analyses.

\section{b. Previous efforts to calibrate radar data with rain gauges}

It is now well recognized that effective radar reflectivity and surface rainfall exhibit a complex relationship that depends on various physical factors that can change significantly from one storm to another and with distance from the radar. However, the importance of using weather radar to estimate rainfall has steadily gained momentum over the past two decades. There are a number of existing schemes that convert radar reflectivity to radar rainfall. The most common method consists of using a power-law $Z-R$ relationship of the form $Z=a R^{b}$. Numerous $Z-R$ relations can be found in the literature (cf. Battan 1973) although individual relations are not universally applicable. The FACE $Z$ $R$ relationship used here, $Z=300 R^{1.4}$, was developed based on summertime convective conditions in Florida.

Significant attention over the past few years has been directed toward the "area-time integral" (ATI)based methods for estimating rainfall. This approach is based on several studies that have documented high correlations in convective cells between horizontal cloud-base area, cloud height, rain volume, and lifetime of the cloud (Hudlow et al. 1979; Gagin et al. 1985; Rosenfeld et al. 1990). Correlation decreases when instantaneous measurements of these cells are made, because of the variability amongst these convective cloud parameters; integration over time and area smoothes the variability and increases the correlation. Consequently, rainfall integrated over space and time may be estimated accurately from time series of the fractional area of reflectivities exceeding a threshold value (Doneaud et al. 1984). Based on a study of Florida rainfall, Lopez et al. ( 1989) found a correlation of 0.92 between the radar-estimated rain volume and ATI for time intervals ranging from $5 \mathrm{~min}$ to $1 \mathrm{~h}$. These results suggested that rainfall over large areas could be accurately measured using a single radar snapshot of storms, ignoring the details of the rain-rate distribution within the 
storm cells. Atlas et al. (1990a) presented a theoretical basis for the successful performance of the ATI method. They attributed the accuracy of the technique to the "existence of a well-behaved PDF (probability density function) of rain rate either from many storms at one instant or from a single storm during its life." The former concept essentially explains the Lopez et al. (1989) results, whereas the latter forms the basis for the Doneaud et al. (1984) observations.

\section{Datasets}

\section{a. WSI regional composite radar images}

The regional composite radar reflectivity images used in this study were produced by the WSI Corporation using input from the lowest level scan of the WSR-57 radars, varying in elevation angle from $0.5^{\circ}$ to $0.9^{\circ}$. The locations of the four radars closest to the CaPE study area (Daytona Beach, Florida; Tampa, Florida; West Palm Beach, Florida; Miami, Florida ) are shown in Fig. 2. Composite reflectivities are given in 0.5 -dBZ intervals at 15 -min intervals on a $2 \mathrm{~km} \times 2$ $\mathrm{km}$ grid; the minimum value is $0 \mathrm{dBZ}$. Reflectivity values for a given grid cell are obtained from each radar, and the "mosaic" image is created by selecting the maximum reflectivity at each grid point.

Proprietary quality control algorithms were applied by WSI to eliminate ground clutter and anomalous propagation prior to forming the composite images. Ground clutter and anomalous propagation were filtered around each radar site based on atmospheric conditions as well as site-specific terrain information. After these algorithms were applied, each image was manually inspected and edited if necessary to remove any remaining spurious echoes. Additionally, all images were examined visually as part of this study to detect any residual errors. Where there were suspicious echoes, GOES imagery and rain gauge observations were used to determine the validity of the radar data. A few cases of anomalous propagation were identified; these images were eliminated from the analysis.

\section{b. Rain gauge network}

As discussed by Duchon et al. (1995), the gauge locations shown in Fig. 1 indicate those gauges that were judged to provide acceptable rainfall for at least some part of the CaPE experiment. Maintenance for these gauges was provided by many organizations: South Florida and Southwest Florida Water Management Districts, Upper St. Johns River Water Management District, U.S. Geological Survey, Kennedy Space Center TRMM Project, National Weather Service, U.S. Air Force, National Center for Atmospheric Research (NCAR), U.S. Dept. of Agriculture. Marshall Space Flight Center, The Florida State University, University of Florida, and University of Georgia. The gauges themselves were of various types including tipping-

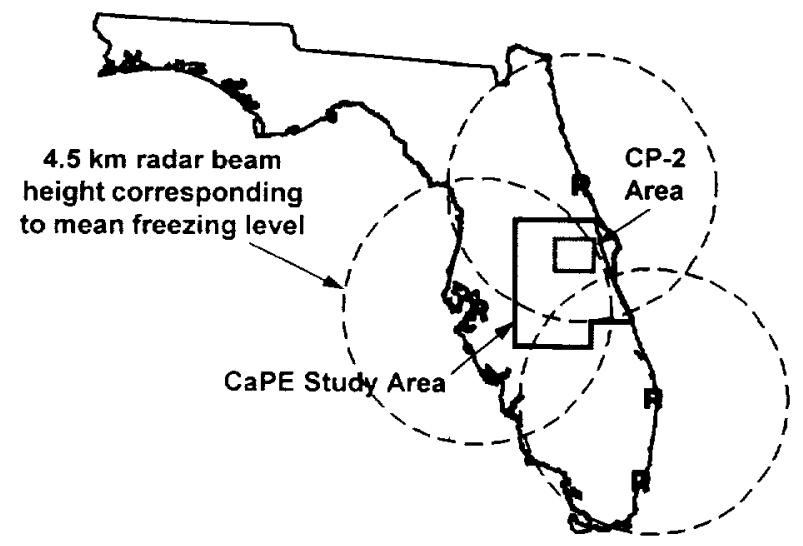

Firi. 2. Locations, indicated by the letter " $R$ ", of the four WSR57 radars used in creating WSI composite reflectivity images, and circles corresponding to a height of $4.5 \mathrm{~km}$ for center of radar beam for the Tampa. Daytona Beach, and West Palm Beach radars. The $4.5-\mathrm{km}$ height approximates the mean freezing level and is at a range of $173 \mathrm{~km}$ from each radar. Also shown are the CaPE study area and a smaller region used in Fig. 4 in comparing composite radar imagery with CP-2 radiar datia.

bucket, weighing-recording, standard can (dipstick), and wedge gauges, and had sampling intervals ranging from I min to I day. Several conditions were used to flag potential gauge problems-large differences between gauge and radar rainfall, large differences between gauges in close proximity to one another, long periods of no precipitation at a gauge, and excessively high rain rates. After identifying these events, various sources, including nearby gauge readings, time series of the gauge data, and in some cases, GOES visible satellite images, were used to decide whether or not the gauge observations were in error. Where there were questionable data, composite radar images were used to determine whether data were acceptable. No changes in gauge amount were made. Through these efforts, erroneous and missing rain gauge reports were identified and eliminated.

Shepard's interpolation scheme (Shepard 1968, 1984 ) was used to create a $2 \mathrm{~km} \times 2 \mathrm{~km}$ field of daily rainfall from the network of gauge observations. Shepard's interpolation is intended for highly spatially variable fields by taking into account the rate of change of rainfall with distance and spatially varying gauge density. This method has been successfully applied at the global scale by Willmott and Legates (1991). Areaaverage daily rainfall for the CaPE study area and the Merritt Island rain gauge area were calculated from the gridded daily rainfall fields, forming the basis of comparison for radar rainfall estimates.

\section{Rainfall estimates using a standard $Z-R$ relationship}

In an initial effort to estimate precipitation over the study area. the FACE $Z-R$ relation $Z=300 R^{1.4}$ was 
applied to the composite reflectivity fields. Reflectivity data at 15 -min time steps were integrated in time to obtain hourly and daily accumulations. Daily rainfall is defined here as 24-h accumulations beginning at 1200 UTC (0700 LST) on the given day. Several options exist for performing the time integration, of which three have been tested: 1) Reflectivities at the start and end of the time period were each converted to rain rates, and the arithmetic mean of the rain rates was used to represent the mean rain rate for the period. 2) The mean of the reflectivities at the start and end of the time period was calculated and converted to rain rate. 3 ) The mean rain rate was determined using the mean value theorem, in which the $Z-R$ relationship is integrated over the range of $Z$ for the time period. The first method is based on the assumption that, over the 15-min interval, the behavior of $R$ is linear, while the other two methods assume that changes in $\mathrm{dBZ}$ are linear in time. The choice of integration scheme is an important issue; average daily rainfall estimated using the FACE $Z-R$ with method 1 is approximately $34 \%$ greater than that using method 2 . Method 3 yields precipitation amounts between methods 1 and 2 , but considerably closer to those of method 2. We have elected to use method 3 ("mean value"' integration) because of its mathematical realism and because it yields the best agreement with rain gauge observations in terms of 14-day total rainfall averaged over the study area.

Radar data were sufficiently continuous to allow calculation of daily totals for 14 of the CaPE study days. Estimates obtained using the FACE $Z-R$ relationship, averaged over the CaPE study area $\left(21000 \mathrm{~km}^{2}\right)$, are compared with the gridded rain gauge means in Fig. 3a. There is substantial day-to-day variability in the ratios of radar-estimated to gauge-measured areal mean precipitation, although the radar estimate is higher on almost every day. For the 14-day period, use of the FACE $Z-R$ relationship overestimates rainfall by approximately $90 \%$ with respect to the gauge mean. This comparison also has been performed for the Merritt Island rain gauge cluster area; results are shown in Fig. 3 b. Over this smaller area, use of the FACE $Z-R$ overestimates total 14-day precipitation by more than $110 \%$. The spatial pattern of radar-rain gauge differences (not shown) over the study area shows that the greatest departures are positive (radar greater than gauge) and occur in the southeastern part of the study area, a region that is shown in Fig. 2 as being at long range from each of the radar sites.

The large differences between radar- and gauge-estimated rainfall emphasize the difficulties associated with estimating convective rainfall using the FACE $Z-$ $R$ relationship in conjunction with the composite radar product. These differences arise from inaccuracies in the gauge measurements as well as factors related to the composite radar data (discussed below), which lead to poor representation of surface precipitation Based on the rain gauge analysis of Duchon et al.
(1995), the uncertainty in daily area-average precipitation from the gauge network is small relative to the magnitude of the radar-rain gauge differences shown in Fig. 3. This is indicated by the standard error of daily area-average rainfall estimated from gauges for five categories of daily rainfall, given in Table 1 . Thus, the emphasis here is on potential sources of errors related to the composite radar data.

There are several sources of error in the radar estimation of surface rainfall. Of these, we consider four to have potentially serious impact on rainfall estimates derived from the WSI composite radar product, and attribute the unsatisfactory performance of the powerlaw $Z-R$ relationship in large part to these factors. These are 1 ) updrafts/downdrafts within a convective cell that result in enhanced reflectivities well above the surface; 2 ) the existence of frozen or mixed phase precipitation within the cloud; 3 ) spreading of the radar beam with increasing range; and 4 ) the algorithm used to create the composite or mosaic reflectivity fields. The WSI compositing technique, which uses the maximum reflectivity from multiple radars, exacerbates the other effects. Selection of the maximum return at each grid point may often lead to the inclusion of many reflectivities from heights near the freezing level in convective cells because of the far range from the viewing radar. In many cases, there may be a closer radar that could provide a low-level scan, while a more distant radar views the cell near the freezing level (for central Florida typically at $4-5 \mathrm{~km}$ ). This results in echoes that are systematically enlarged due to beam spreading and possibly corrupted by frozen or mixed phase hydrometeors.

To give an indication of the degree to which beam spreading and height problems may impact analysis in the $\mathrm{CaPE}$ study area, range circles showing beam heights of $4.5 \mathrm{~km}$ (typical freezing level) for the Tampa, Daytona Beach, and West Palm Beach radars are shown in Fig. 2. These three radars are the closest to the study area and the primary contributors to the composite reflectivity imagery. Much of the area, especially the east central and southeastern portions, is at such a distance from all of the radar sites that any returns from these areas originate from heights near the freezing level. The beam center height $H$ and beamwidth $W$ as a function of distance $D$ from radar are shown in Table 2 . Here $H$ and $W$ have been calculated from ( see Battan 1973)

$$
\begin{gathered}
H=\frac{1}{2} \frac{D^{2}}{R^{\prime}}+D \tan \theta, \\
W=D \tan \phi,
\end{gathered}
$$

where $\theta$ is the radar elevation angle and $\phi$ the radar beamwidth. Also, $R^{\prime}$ is the "effective earth radius," which accounts for radar beam refraction in the earth's atmosphere and is approximated by $4 R / 3$, where $R$ is the earth's radius (Battan 1973). Table 2, together with 

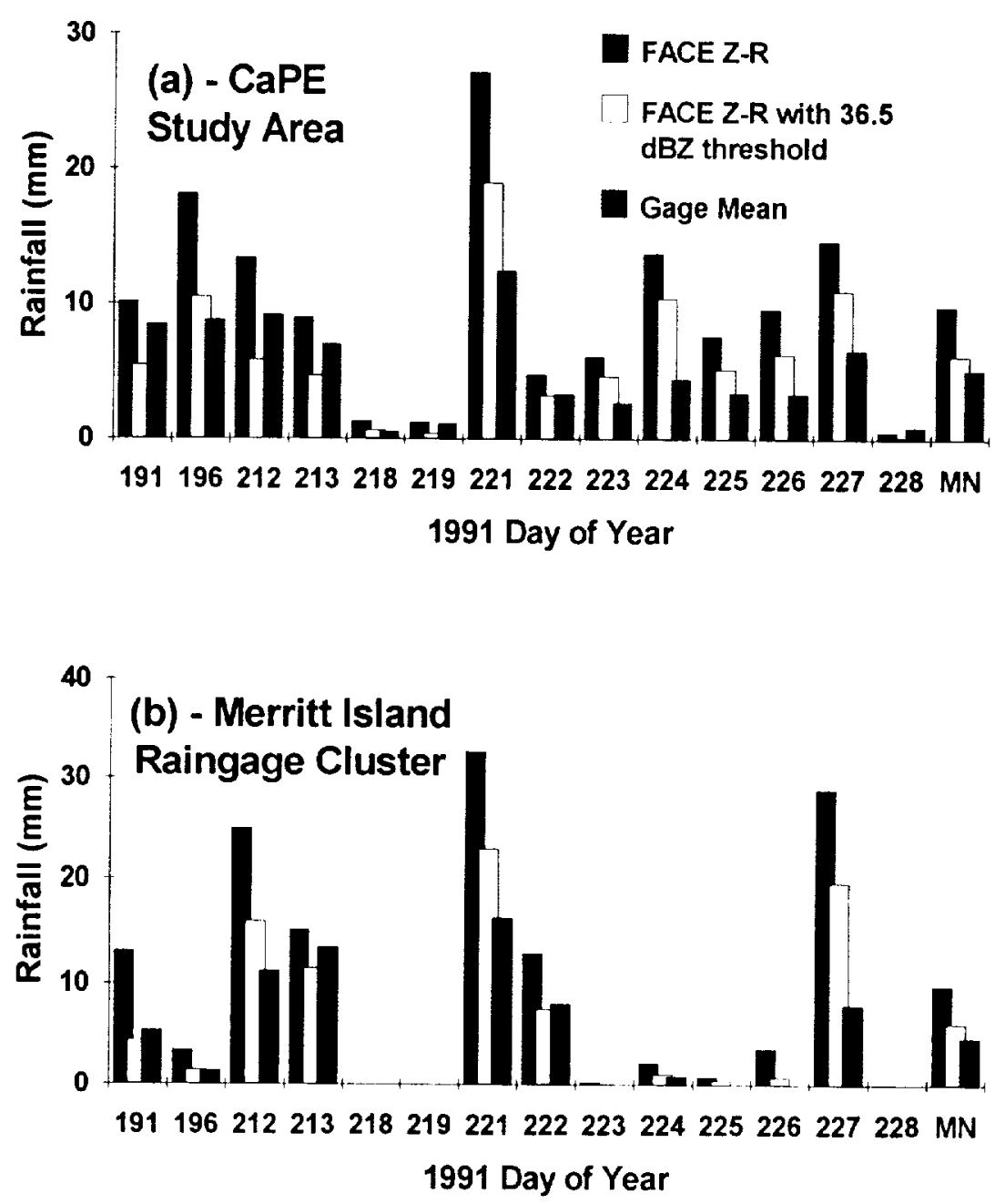

Fig. 3. (a) Daily rainfall estimates for 14 days and the 14 day mean rainfall (indicated by $M N$ ) for the CaPE study area derived from the gridded rain gauge fields and from the WSI composite radar images using the FACE $Z-R$ relationship $Z=3(0) R^{1.4}$. Results are shown for the FACE relationship with and without a $36.5-\mathrm{dBZ}$ reflectivity threshold. (b) Same as (a) except for the Merritt Island rain gauge cluster area.

Fig. 2, indicates that for a significant portion of the region. rainfall is being estimated using radar volumes whose depth and width is greater than $5 \mathrm{~km}$. Since the horizontal dimension of the radar volume is greater than the composite grid resolution of $2 \mathrm{~km} \times 2 \mathrm{~km}$, the corresponding pixel values are multiply sampled to fill the grid.

Spreading of the radar beam away from the radar site affects rainfall estimates by distributing the return signal across the radar measurement volume. Discrepancies between observed reflectivities and those that would be measured by a sensor with an infinitesimally narrow beam (or equivalently one at infinitesimally close range) arise when the precipitation field is nonuniform. These may be extreme when large reflectivity gradients (either horizontal or vertical) exist within the beam volume, especially if the echo region only partially fills the volume (Rosenfeld et al. 1992). Peak values in the actual reflectivity field usually will be reduced by signal averaging, but the areal coverage of the rain area will be increased. Rosenfeld et al. (1992) used a simulation approach and showed that gradients in the actual rain field result in very substantial overestimates of the rain area as well as the area-integrated rainfall. For isolated convective cells, they estimate the bias (ratio of radar to surface rainfall) to range from 1.0 at a range of $0 \mathrm{~km}$ to a maximum of 1.4 at a range of approximately $120 \mathrm{~km}$. The bias then decreases, becoming 1.0 at $200 \mathrm{~km}$ and less than unity at longer ranges.

The manifestation of these effects in the composite radar imagery is illustrated in Fig. 4 through a com- 
TAB 1 1. Standard error of daily area-inerage rainfall due to spatial simpling and random and systematic measurement errors, for tive categaries of daily mean rainfall. Results are from Duchon ot al. (1995), based on rain gauge analysis for 40 days during the CaPE. experiment.

\begin{tabular}{cccc}
\hline \hline $\begin{array}{c}\text { Daily mean } \\
\text { rainfall (mm) }\end{array}$ & $\begin{array}{c}\text { Number } \\
\text { of days }\end{array}$ & $\begin{array}{c}\text { Number } \\
\text { of galuges }\end{array}$ & $\begin{array}{c}\text { Standard error of daily } \\
\text { area-average rainfall } \\
\text { (mm) }\end{array}$ \\
\hline 21 & 8 & 103 & 0.27 \\
$1-3$ & 7 & 101 & 0.56 \\
$3-7$ & 11 & 100 & 0.89 \\
$7-11$ & 8 & 100 & 1.17 \\
$11-15$ & 6 & 101 & 1.49 \\
\hline
\end{tabular}

parison with reflectivity fields observed by the NCAR CP-2 multiparameter radar, a dual-polarization dualwavelength research system operating at $\mathrm{S}$ - and $\mathrm{X}$-band frequencies (Bringi and Hendry 1990). CP-2 multiparameter measurements from CaPE had a range resolution of $250 \mathrm{~m}$ while the beamwidth at $\mathrm{S}$-band was approximately $1^{\circ}$. The raw polar $1^{\circ} \times 250 \mathrm{~m}$ resolution $S$-band reflectivity data were converted to constant-altitude plan position indicators (CAPPIs) having horizontal grid resolution of $500 \mathrm{~m}$. In Fig. 4, reflectivity CAPPIs at 1-, 2-, 3-, 4-, and 5-km height are shown for a $50 \mathrm{~km} \times 40 \mathrm{~km}$ region immediately inland from Cape Canaveral (see Fig. 2). The observations are for 0115 UTC 13 August 1991. Distances from the three closest WSR-57 radars to the midpoint of this region, and the height of the radar beam center (above ground level) for the image area are as follows: Daytona Beach - 90 $\mathrm{km} / 1.9 \mathrm{~km}$; Tampa $-150 \mathrm{~km} / 3.7 \mathrm{~km}$; West Palm Beach $-220 \mathrm{~km} / 6.2 \mathrm{~km}$. Thus, the Daytona Beach system provided returns at fairly low levels, the Tampa radar sampled both above and below the freezing level, while the West Palm Beach radar sampled very large volumes, primarily above the freezing level. Due to its proximity to the study area, it is expected that the Daytona Beach site contributed the greatest weight to the composite reflectivity field, but this assumption cannot be verified.

The five CP-2 CAPPIs in Fig. 4 show the vertical structure of a well-developed multicell convective complex. Some data are missing in the CAPPIs above $1 \mathrm{~km}$ due to the scan configuration. There are two main areas of high reflectivity ( $>50 \mathrm{dBZ}$ ), one in the northwest and the other in the east central portion of the image. These cells are evident at each level, with the most intense returns (reflectivity in excess of $55 \mathrm{dBZ}$ ) reaching maximal coverage at a height of $5 \mathrm{~km}$. Regions of reflectivity exceeding $50 \mathrm{dBZ}$ are most pronounced at 3 or $4 \mathrm{~km}$, while moderate echo regions ( $40-50 \mathrm{dBZ}$ ) become smaller above $4 \mathrm{~km}$. The areal coverage of the entire complex (as defined by $10-\mathrm{dBZ}$ reflectivities) is fairly uniform with height. being only slightly higher at the lowest levels. While the basic structure of the strong cells in this convective system observed by the CP-2 and the composite image is similar, there is significant enlargement of the echo region in the composite. The area for which $\mathrm{dB} Z>50$ is comparable between the composite and the CP-2 CAPPIs, but the area where $\mathrm{dB} Z>35$ is approximately twice as large in the composite reflectivity field than in the l-km CAPPI. This comparison illustrates the areal enlargement of precipitation resulting from the wide $\left(2.2^{\circ}\right)$ beam of WSR-57 radars as compared with the relatively narrow $\left(1^{\circ}\right)$ beam of the $\mathrm{CP}-2$ radar. Because of the expansion of the precipitation area resulting from beam spreading and the compositing technique, use of the FACE $Z-R$ relationship with the composite radar product results in very large biases in precipitation estimates.

Figure 4 indicates that regions of low and moderate reflectivity are overrepresented in the composite imagery, leading to overestimation of both the "rain" area $(\mathrm{dBZ}>0)$ and area-average rainfall. To counteract this effect, the FACE $Z-R$ relationship has been applied using a threshold reflectivity; that is, no rainfall is associated with reflectivities below some minimum value. We have chosen a threshold such that the resulting rain area approximates that which is observed by the gauge network. In the following section it is shown through analysis of rain-rate and reflectivity distributions that the appropriate reflectivity threshold for the composite radar data is approximately $36.5 \mathrm{dBZ}$. It was found that, on average, $28 \%$ of all radar pixels and $81 \%$ of "rain" pixels satisfy $0<\mathrm{dBZ}<36.5$. Areaaverage daily rainfall calculated by applying this threshold to the FACE $Z-R$ relationship is shown in Fig. 3, along with the unmodified FACE $Z-R$ results, for the CaPE study area and the Merritt Island cluster. Although the FACE rain rate associated with $36.5 \mathrm{dBZ}$ is only $6.9 \mathrm{~mm} \mathrm{~h}^{-1}$, the high frequency of occurrence of reflectivities less than $36.5 \mathrm{dBZ}$ contributes significantly to the total rainfall. By applying a 36.5-dBZ threshold to the FACE $Z-R$, the total rainfall is reduced by $36 \%$ and $38 \%$ for the large and small study areas. However, use of the FACE relationship still overestimates area-average daily rainfall by $21 \%$ and $33 \%$ for the two areas. All subsequent FACE rainfall estimates

TABLE 2. Height of WSR-57 radar beam center, and width and depth of beam as a function of distance from radar. Calculations based on a $2.2^{\circ}$ beam and an elevation angle of $0.9^{\circ}$.

\begin{tabular}{ccc}
\hline $\begin{array}{c}\text { Distance from } \\
\text { radar }(\mathrm{km})\end{array}$ & $\begin{array}{c}\text { Beam center } \\
\text { height }(\mathrm{km})\end{array}$ & $\begin{array}{c}\text { Beamwidth } \\
\text { and depth }(\mathrm{km})\end{array}$ \\
\hline 25 & 0.4 & 1.0 \\
50 & 0.9 & 1.9 \\
7.5 & 1.5 & 2.9 \\
100 & 2.2 & 3.8 \\
150 & 3.7 & 5.7 \\
200 & 5.5 & 7.7 \\
250 & 7.6 & 9.6 \\
\hline
\end{tabular}




\section{CP-2 $1 \mathrm{~km}$}

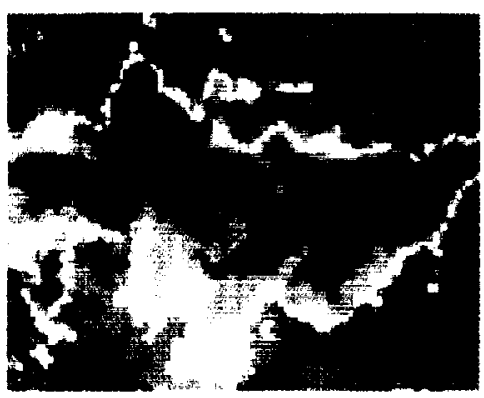

CP-2 $3 \mathrm{~km}$

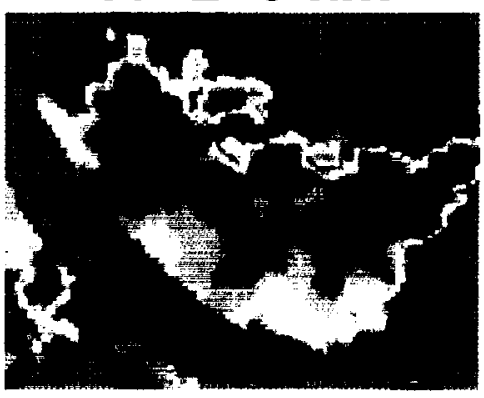

CP-2 5 km

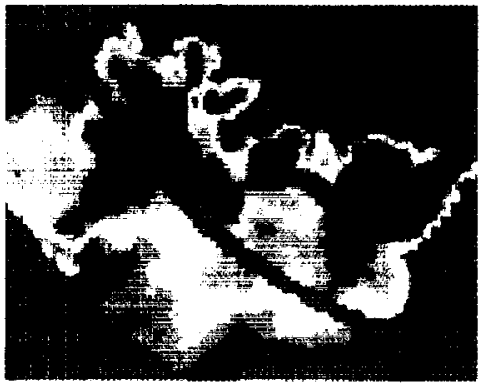

CP-2 2 km

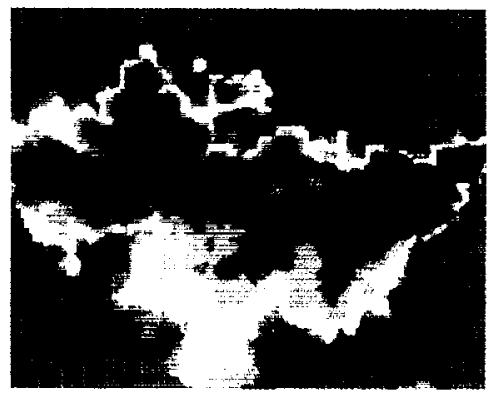

CP-2 $4 \mathrm{~km}$

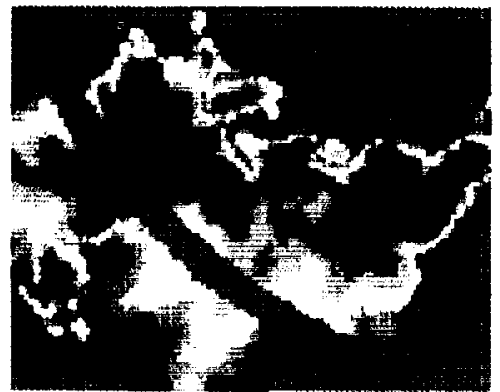

WSI Composite

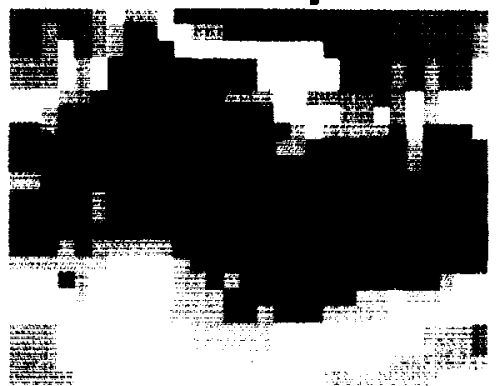

$10 \mathrm{~km}$

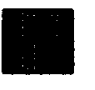

$<10 \mathrm{dBZ}$

$10-20 \mathrm{dBZ}$

$20-25 \mathrm{dBZ}$

$\square 25-30 \mathrm{dBZ}$

30 - 35 dBZ

$355-40 \mathrm{dBZ}$

$40-45 d B Z$

45 - $50 \mathrm{dBZ}$

50 - $55 \mathrm{dBZ}$

$>55 \mathrm{dBZ}$

Frg. 4. CAPPIs of reflectivity at $1-, 2-, 3-, 4-$, and $5-\mathrm{km}$ heights derived from $\mathrm{CP}-2$ volumetric radar scans, and WSI composite reflectivity image in east-central Florida at 0115 UTC 1.3 August 1991. Region is shown in Fig. 2 and is approximately $50 \mathrm{~km} \times 40 \mathrm{~km}$. 
shown in this paper are based on application of the 36.5-dBZ threshold. This adjustment eliminates reflectivities that do not, in a statistical sense, correspond to rain areas, and is necessary to legitimize comparisons between FACE and PMM rainfall estimates.

\section{Rainfall estimates using the probability matching method (PMM)}

\section{a. Theory and application}

Recently, there has been an emphasis on deriving $Z-$ $R$ relations that are tuned to the local climatology and radar system. Calheiros and Zawadzki (1987) proposed the technique now referred to as the probability matching method to derive $Z-R$ relations aimed at generating accurate estimates of rainfall over areas and time intervals large enough to encompass multiple rain systems at various stages of maturity. They demonstrated that their approach, based on forcing the PDF of $Z$ to mimic the PDF of $R$, results in accurate estimates of "long-term (average)" accumulations. This approach eliminates the requirement for simultaneous radar-gauge measurements as long as the gauge measurements represent a sample of the local climatology. Variations of this technique have been developed since and applied successfully by Atlas et al. (1990b, 1993) and Rosenfeld et al. (1993, 1994). A $Z-R$ relationship derived using a PMM approach is sometimes referred to as a "climatologically tuned" relationship since it is based on the statistical distributions of $Z$ and $R$, which represent the precipitation "climatology" of the given space-time domain. These methods often involve stratification according to rain type and distance from the radar. The relationship is "tuned" in the sense that the radar-derived rain-rate distribution (and thus the volumetric rainfall, given by the first moment of rain rate) is equivalent to that measured by the gauges. Properties of the radar system - frequency, calibration, beam geometry, and position of the radar(s) within the region of study - also affect the obtained relationship.

Conceptually, the applicability of the PMM is limited to rainfall estimation over space-time domains that are large enough to adequately sample these distributions. Atlas et al. (1990b) warn that the PMMbased $Z-R$ relation should not be applied at a point in space or time. The minimum appropriate space and timescales are likely a function of the local climatology, that is, frequency and diversity of precipitation events. As stated above, one of the objectives of this study is to examine the errors associated with applying the PMM $Z-R$ relationship to composite radar data on various space and timescales, and thus define the minimum scales on which application of this technique is warranted.

The principle of the PMM, as formulated by Calheiros and Zawadzki ( 1987), is to construct a $Z-R$ relationship based on $Z_{i}, R_{i}$ pairs such that cumulative distribution functions (CDFs) of $Z$ and $R$ match; that is, pairs that satisfy

$$
\int_{R_{\bar{\tau}}}^{R_{i}} P(R) d R=\int_{Z_{\bar{\tau}}}^{Z_{i}} P(Z) d Z,
$$

where $P(\quad$ ) represents a probability density function and $R_{\tau}$ and $Z_{\tau}$ are threshold values. In this paper, we are following the modified procedure described by Atlas et al. (1990b), in which the CDFs are derived for the first moments of $Z$ and $R$ according to

$$
\frac{\int_{R_{\tau}}^{R_{i}} R P(R) d R}{\int_{R_{\tau}}^{\infty} R P(R) d R}=\frac{\int_{Z_{\tau}}^{Z_{i}} Z P(Z) d Z}{\int_{Z_{\tau}}^{\infty} Z P(Z) d Z} .
$$

In practice, the $Z_{i}, R_{i}$ values are found by approximating (4) with discrete summations. Use of the first moment ensures that the $Z_{i}, R_{i}$ pairs are well distributed over the high rain rates, which account for most of the accumulated rainfall. In addition, the total observed rainfall is exactly reproduced by the obtained $Z-R$ relationship when applied to the reflectivity data used in deriving the relationship.

The PMM was applied using composite radar reflectivity and rain gauge data from five days during CaPE - 10 July (day 191), 15 July (196), 26 July (207), 27 July (208), and 15 August (227). Three of these days (191, 196, and 227) are included in the daily accumulations shown in Fig. 3. On each day, only the time period 1400-0400 UTC was used, as very little rain occurred outside of this time period. The five days selected include a variety of synoptic-scale wind regimes, shown by Frank et al. (1967) to control the geographic distribution of deep convection in Florida. The remaining 11 days of the complete dataset were used for validation of the technique. To construct the reflectivity $\mathrm{PDF}$, radar pixel values from all available 15-min images were sampled at every fourth line and element within the grid to provide effectively independent samples. Data were used only for the eastern and central portions of the CaPE study area, which had a rather dense concentration of 1-min rain gauges. This ensures that gauge and radar measurements both adequately sampled the precipitation conditions over the area. The histogram in Fig. 5a shows the frequencies of occurrence of reflectivity in 1-dBZ bins expressed as a percentage of the total number of observations for which $\mathrm{dB} Z>0$. In creating the histogram, reflectivities greater than $55 \mathrm{dBZ}$ were excluded from the analysis. This had negligible impact on the histogram, as these events constitute only $0.06 \%$ of all data.

The time interval over which rainfall measurements have been accumulated was determined by the equation (Zawadzki 1975)

$$
\Delta t=\frac{1.3 A^{1 / 2}}{V}
$$




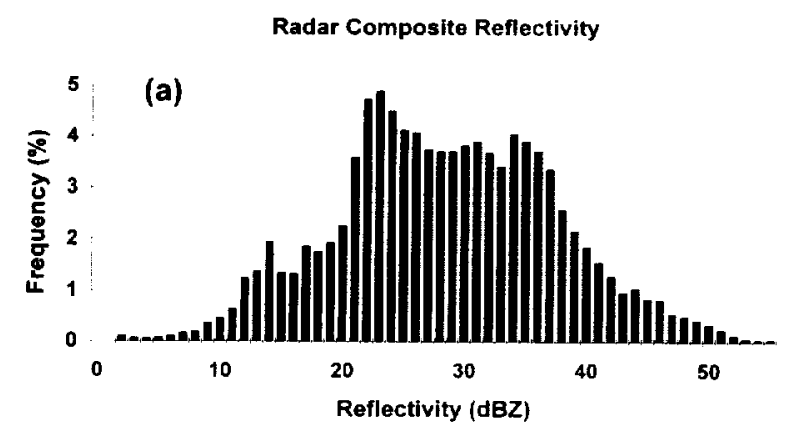

Rainrates from Raingage Network

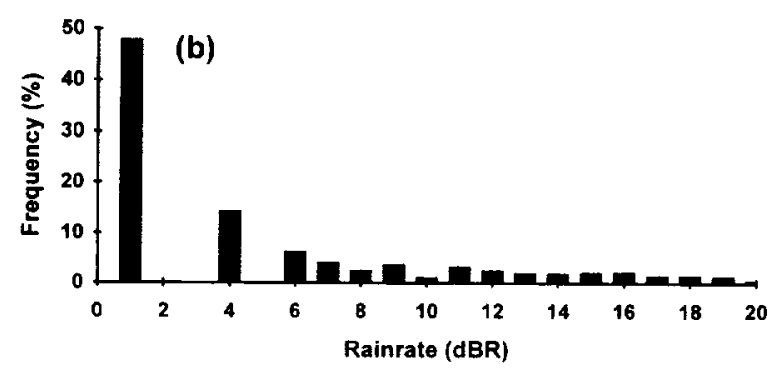

FIG. 5. (a) Histogram of reflectivity values obtained from five days of 15-min WSI composite radar images. Bin width is $1 \mathrm{dBZ}$. Values represent frequency of occurrence relative to the total number of pixels having reflectivities greater than $0 \mathrm{dBZ}$. (b) Histogram of 12-min rain rates for the five days used in PMM analysis. Bin width is 1 $\mathrm{dB} R$. Values represent frequency of occurrence relative to the total number of rain gauge observations indicating nonzero precipitation.

where $A$ is the radar beam cross-sectional area and $V$ is the horizontal velocity of the rain cell. Using a beamwidth of $3.5 \mathrm{~km}$ (representative of a range of $100 \mathrm{~km}$ ), and $V=20 \mathrm{~km} \mathrm{~h}^{-1}, \Delta t=12 \mathrm{~min}$. This is the rain gauge time constant analogous to the horizontal $\mathrm{di}$ mension of the radar beam. It was found by Zawadzki (1975) to be the optimal integration period for comparing rain rates with reflectivities to ensure consistency between the radar spatial resolution and the temporal resolution of the gauge measurements. Rain rates were determined for each 12 -min period for the 68 rain gauges that recorded at $1-$ min intervals. The histogram based on these rain rates is shown in Fig. 5b. The discontinuous nature of the histogram at low rain rates is due to the fact that the minimum precipitation amount measurable by the gauges is $0.0 \mathrm{I}^{\prime \prime}$, which translates to a minimum detectable rain rate for a $12-\min$ period of $1.27 \mathrm{~mm} \mathrm{~h}$ ', or $1.04 \mathrm{dBR}$, while the next larger rate is $2.54 \mathrm{~mm} \mathrm{~h}$ ', or $4.05 \mathrm{~dB} R$, where $\mathrm{dB} R$ is equal to $10 \log (R)$.

To determine the CDFs of $Z$ and $R$ and calculate the $Z-R$ relationship from (4), the threshold values $R_{\tau}$ and $Z_{\tau}$ must be defined. In the cast of $R_{-}$. the minimum detectable rain rate is $1.04 \mathrm{~dB} R$. Here $Z$, is then chosen so that the percent of the space-time domain over which $Z \geqslant Z_{-}$is equivalent to the percent of the space- time domain for which $R \geqslant R_{\tau}$. Based on the rain gauge measurements, $R \geqslant R_{\text {- }}$ (i.e., some precipitation measured within the 12-min accumulation period) $9.9 \%$ of the time. In contrast, composite reflectivity values exceed $0 \mathrm{dBZ} 34.7 \%$ of the time for the five daily periods used in the PDF analysis. This result is supported by Fig. 4, which shows that the size of rain echoes is exaggerated in the composite images by the beam spreading and range effects discussed earlier. This indicates that regions of low reflectivities do not, in a statistical sense. correspond to surface precipitation. To produce a consistent proportion of "rain" area, $Z_{\tau}$ must be set to $34 \mathrm{~dB} Z$, a threshold similar to values between 31 and $43 \mathrm{~dB}$. (increasing with range) reported by Rosenfeld et al. ( 1993 ) for isolated convection.

Based on the threshold values $R_{\tau}$ and $Z_{r}$, the conditional CDFs for the first moments of $R$ and $Z$ were calculated at $1-\mathrm{dB}$ intervals and plotted in Fig. 6. Smooth curves were drawn through these points, and $\mathrm{dB} R, \mathrm{~dB} Z$ pairs determined for a number of probability values. The resulting $\mathrm{dB} Z-\mathrm{dB} R$ plot suggested that a quadratic regression function was most appropriate. The best-fit equation was found to be

$$
\mathrm{dB} Z=36.34-0.111 \mathrm{~dB} R+0.049 \mathrm{~dB} R^{2},
$$

or upon inverting,

$$
\mathrm{dB} R=1.129+(20.33 \mathrm{dBZ}-737.3)^{0.5},
$$

with $r^{2}=0.998$. The functional relationship between rain rate and reflectivity as given by ( 7$)$ is shown along with the FACE $Z-R$ relationship in Fig. 7. Due to the

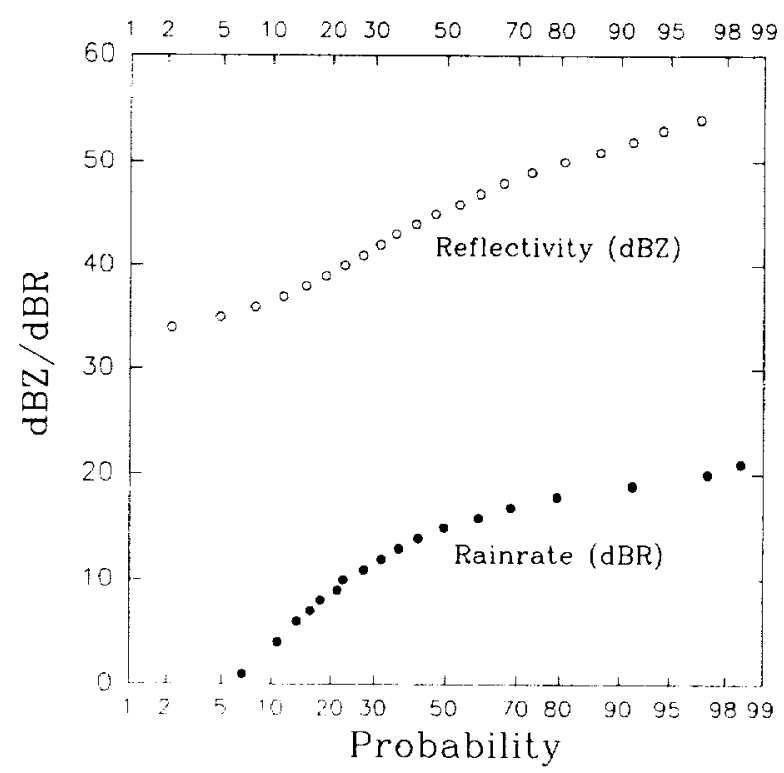

Fig. 6. Cumulative distribution functions for the tirst moments of radar rellectivity and gauge rain rate for the data used in PMM anal$y$ sis. The $Z$ distribution is based on a threshold of $34 \mathrm{dBZ}$. Abscissat is plotted on Giansian probability seale. 


\section{Comparison of Z-R Relationships}

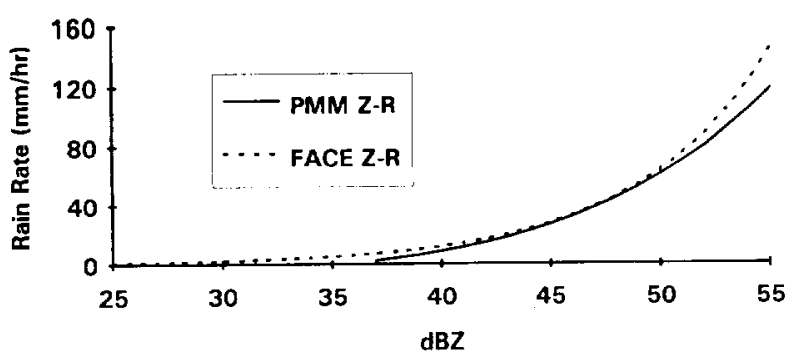

Fici. 7. Radar rain rate $\left(\mathrm{mm} \mathrm{h}{ }^{1}\right)$ derived from the FACE $Z-R(Z$ $=300 R^{1,4}$ ) and the PMM-based $Z-R$ relationship plotted against radar reflectivity.

square root function in $(7)$, the $Z-R$ relationship is valid only for $\mathrm{dBZ}>36.27$.

For all reflectivity values, the PMM $Z-R$ produces lower rain rates than does the FACE $Z-R$, although the difference is significant only above about $50 \mathrm{dBZ}$. The two relationships yield very similar rain rates between 40 and $50 \mathrm{dBZ}$. An important point is that the 36.27$\mathrm{dBZ}$ threshold (in practice $36.5 \mathrm{dBZ}$ ) used in the PMM $Z-R$, which has also been imposed in this study in estimating rainfall from the FACE relationship, reduces the fractional coverage of radar-derived precipitation to be consistent with the coverage observed in the rain gauge data, and in doing so substantially decreases the area-average rainfall estimates. The PMM estimates are substantially lower than FACE estimates even when the 36.5-dBZ threshold is applied to the FACE calculations.

\section{b. Intercomparisons between radar and rain gauge precipitation at point locations}

The PMM and FACE $Z-R$ relationships have been applied over various space and time domains. In this section precipitation estimated from the radar composites at points corresponding to rain gauge locations is compared with gauge accumulations over hourly and daily periods, as well as for the collective 11-day period excluding the time periods used in deriving the PMM $Z-R$. The 36.5-dBZ threshold was applied in the FACE calculations. Results based on the 11-day period provide an independent measure of the accuracy of the PMM technique as applied to the composite imagery. Radar precipitation estimates for rain gauge locations were calculated in two ways: as a single pixel value at the gauge location, and as the mean rainfall over 3 pixel $\times 3$ pixel $(6 \mathrm{~km} \times 6 \mathrm{~km}$ ) regions centered at the gauge site. This averaging was performed to minimize crrors associated with timing, image geolocation, and winddriven rain shafts. However, since means based on single pixels and $3 \times 3$ pixel regions were found to be very similar, results are presented here for the single pixel case only. Table 3 shows mean rain gauge-, FACE-, and PMM-based rainfall estimates for hourly, daily, and multiday periods, as well as root-meansquare error (rmse) between the radar estimates and gauge observations.

Results for hourly rainfall from FACE and PMM Z$R$ relationships are shown in the form of scatterplots in Fig. 8. Each point represents an hourly accumulation at one rain gauge for one of the $53 \mathrm{~h}$ used in the PMM analysis. The rmse values for the two methods ( Table 3) are similar to one another and are much higher than mean rain gauge estimates. The overall mean gauge rainfall is $0.95 \mathrm{~mm} \mathrm{~h}^{-1}$, whereas the mean PMM rainfall is slightly less $\left(0.87 \mathrm{~mm} \mathrm{~h}^{-1}\right)$, and the mean FACE rainfall is higher at $1.02 \mathrm{~mm} \mathrm{~h}^{* 1}$. Figure 8 illustrates the tendency of both $Z-R$ relationships to underestimate large gauge-measured hourly rainfall and overestimate small amounts. This may be related to the typically small convective cells in this environment, which have diameters of $2-4 \mathrm{~km}$. In those events when the most intense rainfall within a thunderstorm occurs precisely at a gauge location, the reflectivity for the relatively large radar volume underestimates the maximum intensity at the gauge. On the other hand, intense rain cells that are in close proximity to a gauge but do not track directly over a gauge often produce large radarrainfall estimates and little or no rain in the gauge.

Daily rainfall comparisons are shown in Fig. 9. Each observation is a daily accumulation from radar or rain gauge; only the 11 independent days are included. The scatter is large for both FACE and PMM methods, as rmse values for both methods (Table 3 ) are more than double the mean rain gauge values. The mean FACEderived rainfall of $6.14 \mathrm{~mm}$ day $^{-1}$ is $45 \%$ higher than

TABIE 3. Statistics for hourly, daily and multiday rainfall estimates at gauge locations for FACE and PMM $Z-R$ relationships. Given are gauge and radar means and the square rool of the mean-square error (rmse). FACE estimates are based on $36.5-\mathrm{dBZ}$ threshold.

\begin{tabular}{|c|c|c|c|c|}
\hline $\begin{array}{c}\text { Time } \\
\text { periods }\end{array}$ & & $\begin{array}{c}\text { Giluge } \\
\text { mean } \\
(\mathrm{mm})\end{array}$ & $\begin{array}{l}\text { Radar } \\
\text { mean } \\
(\mathrm{mm})\end{array}$ & $\begin{array}{l}\text { rmse } \\
(\mathrm{nmm})\end{array}$ \\
\hline \multirow[t]{3}{*}{ Hourly } & All hours (53) & & & \\
\hline & FACE & 0.95 & 1.02 & 3.42 \\
\hline & PMM & 0.95 & 0.87 & 3.30 \\
\hline \multirow[t]{6}{*}{ Daily } & All days (14) & & & \\
\hline & FACE & 5.07 & 7.15 & 11.25 \\
\hline & PMM & 5.07 & 6.13 & 10.45 \\
\hline & Independent days (11) & & & \\
\hline & FACE & 4.20 & 6.14 & 10.81 \\
\hline & PMM & 4.20 & 5.32 & 10.13 \\
\hline \multirow[t]{6}{*}{ Total Period } & All days (14) & & & \\
\hline & FACE & 69.7 .3 & 98.40 & 47.36 \\
\hline & PMM & 69.73 & 84.43 & 38.38 \\
\hline & Independent days (11) & & & \\
\hline & FACE & 45.60 & 66.68 & 39.47 \\
\hline & PMM & 4.5 .60 & 57.78 & 33.74 \\
\hline
\end{tabular}



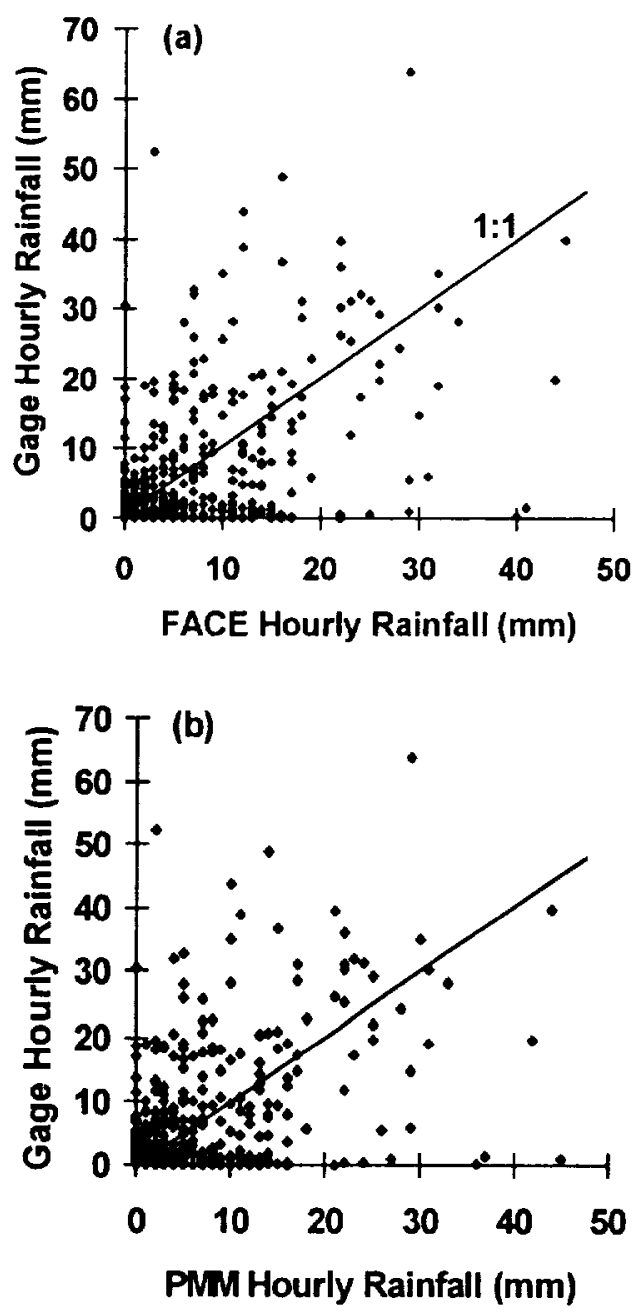

FIG. 8. (a) Scatter diagram of hourly radar rainfall estimates obtained using the FACE $Z-R$ relationship compared with rain gauge measurements. Data consist of $53 \mathrm{~h}$ used in PMM analysis. (b) Same as (a) except for PMM rainfall estimates.

the gauge mean ( $4.20 \mathrm{~mm}$ day '). The PMM estimates also are positively biased with respect to the gauge mean, by approximately $25 \%$.

Radar estimates of total rainfall for the independent 11-day period are compared with gauge measurements in Fig. 10. The correlation coefficients for FACE and PMM are quite small at 0.39 and 0.37 . Relative to the gauge means, rmse values are much lower than for hourly and daily precipitation. but are still quite large $-87 \%$ and $74 \%$ of the gauge mean for FACE and $P M M Z-R$ relationships, respectively. The positive bias of the FACE retrievals is evident in the top panel, as the majority of the points lie below the $1: 1$ line. This is true to a lesser degree in the PMM estimates.

A comment is warranted regarding linear correlation coefficients for hourly, daily, and total rainfall at point locations. Surprisingly, the calculated coefficients were largest for hourly estimates and smallest for the 11-day period. However, the scatter diagrams for hourly and daily rainfall estimates in Figs. 8 and 9 indicate dense clusters of points near the origin, and increasing scatter of the points as rainfall increases along either axis. This indicates the presence of heteroscedasticity, or an increase of variance with rainfall amount (Afifi and Azen 1972), a condition that does not appear to exist for the 11-day precipitation estimates shown in Fig. 10. The existence of heteroscedasticity is a violation of the assumptions made concerning residuals in a simple linear regression model, therefore, the hourly and daily correlation coefficients are meaningless, and a comparison of correlation coefficients with those obtained for the total period is not valid.

Based on these point-scale comparisons, we conclude that application of neither FACE nor PMM technique is appropriate for the retrieval of point rainfall.
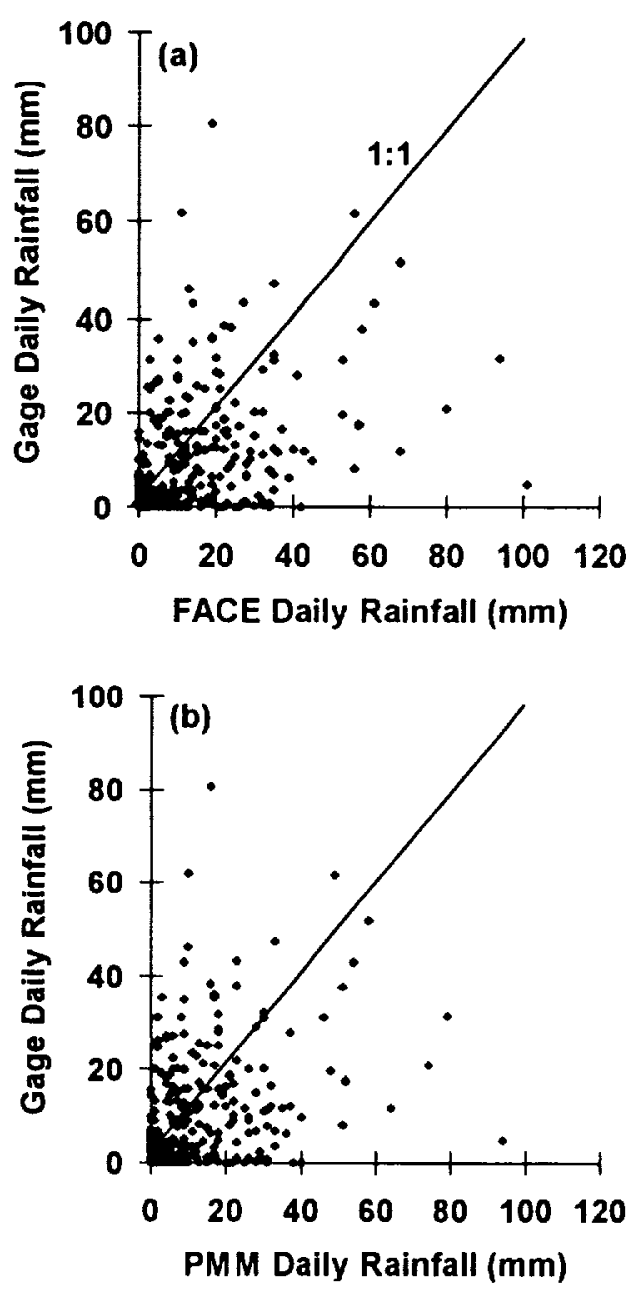

Fig. 9. (a) Scatter diagram of daily radar rainfall estimates obtained using FACE $Z$ - $R$ compared with measurements. Data consist of the 11 days not used in deriving the PMM $Z-R$ relationship. (b) Same as (a) except for PMM rainfill estimates. 

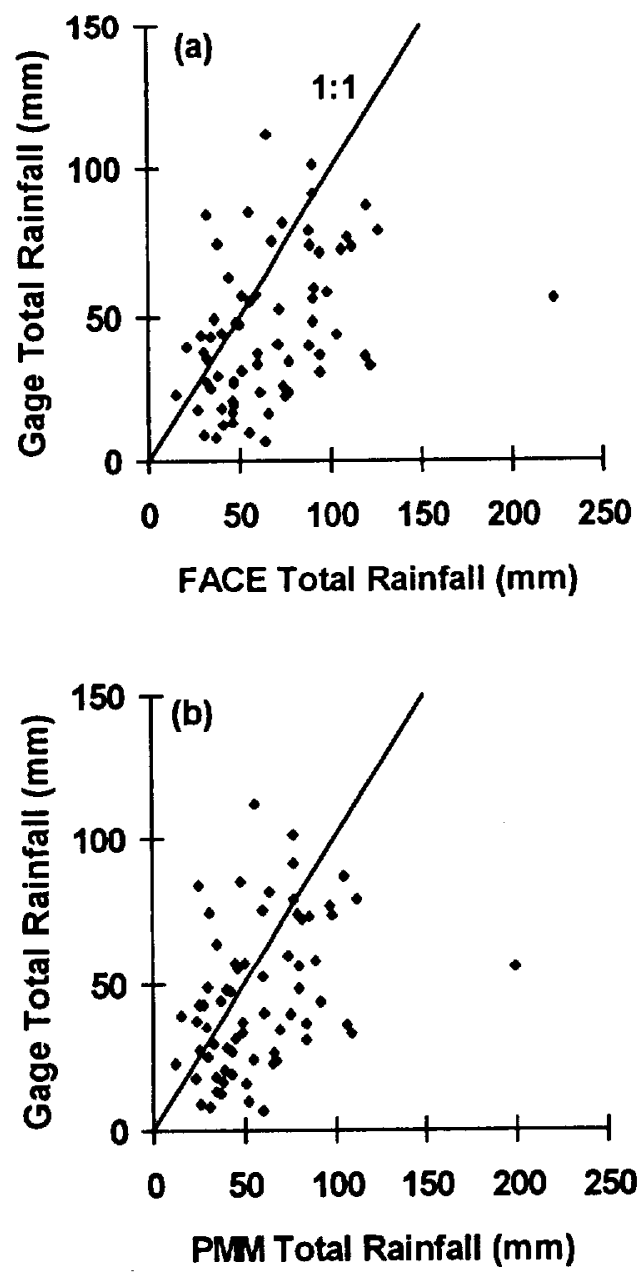

Fig. 10. (a) Scatter diagram of 11-day total rainfall estimates obtained using FACE $Z-R$ compared with rain gauge measurements. (b) Sume as (a) except for PMM rainfall estimates.

at least on timescales of two weeks or less. This in agreement with Atlas et al. (1990b), who state that the PMM should not be applied in points in space or time. We feel that the low correlations and large rmse's for point-scale precipitation estimation are due to two factors. The first is that attempts to correlate radar and rain gauge observations at points in space and time rely on nearly perfect registration of the radar imagery in space, as well as excellent time tagging of both radar and rain gauge data. It is not surprising that there are large discrepancies between radar reflectivity and gauge-observed rain rates, especially in a highly convective domain such as Florida where the typical dimension of convective cells is only about $2-4 \mathrm{~km}$. A registration error of one pixel or an error of a few minutes in either gauge or radar observation time will seriously degrade any connection between reflectivity and rain rate. A related complication is the downwind advection of raindrops. Under certain conditions, the horizontal distance between the location of a raindrop as detected by radar and its terminal position at ground level may easily exceed $1 \mathrm{~km}$. This adds additional error to coincident radar-rain gauge comparisons.

The second obstacle to rainfall estimation at points in time and space lies in the assumptions of the PMM method. At a given gauge location, typically only a few rain events occur over the time periods used in this study. Thus, the PMM requirement that the sampling must capture the full statistical nature of the relationship between reflectivity and rain rate is not met, even for the 11-day integration periods. However, this same restriction does not apply to the FACE method, which performed worse than the PMM at the point scale. This implies that the more important problems in estimating rainfall from radar at points in space and time are those related to the aforementioned errors in geolocation and timing of the radar and rain gauge data.

\section{c. Intercomparisons between radar and rain gauge area-average daily precipitation}

Daily area-average rainfall estimates have been obtained from the FACE and PMM $Z-R$ relationships and are compared in this section with rainfall measured by the gauge network over the study area and the smaller Merritt Island gauge cluster. Rainfall estimates based on the PMM $Z-R$ using "mean value" time integration for the 14 daily periods are compared with means from the gridded rain gauge product in Fig. 11. Daily totals are for 24-h periods beginning at 0700 LST on the given day. Using the PMM $Z-R$ relation, the daily ratio of radar to gauge rainfall varies from 0.5 to 2.1 for the larger area and from 0.6 to 1.9 for the cluster region, excluding days for which mean precipitation is less than $2 \mathrm{~mm}$. Relative to FACE $Z-R$ estimates (Fig. 3 ), the overall bias is much reduced, as shown by the 14day means. The PMM estimates are approximately $5 \%$ and $11 \%$ greater than the gauge amounts for the CaPE region and the cluster area, respectively, compared to $21 \%$ and $33 \%$ overestimates obtained from the FACE $Z-R$ using a $36.5-\mathrm{dBZ}$ threshold. Because the PMM $Z-R$ relationship was determined using data from only three of these 14 days (days 191, 196, and 227), the relatively small biases shown in Fig. 11 and Table 4 are based mostly on the 11 independent days, an encouraging result for application of the PMM method to daily area-average rainfall. The PMM relationship represents a substantial improvement in bias with respect to the FACE $Z-R$ when averaged over these areas and over 14 days.

Correlation coefficients and rmse's, relative to rain gauge means, for area-average daily rainfall estimates for FACE and PMM methods are given in Table 4. These statistics relate to the daily precipitation estimates shown in Fig. 3 (FACE) and Fig. 11 (PMM) estimates. For both geographic regions, rmse is smaller for the PMM than for the FACE $Z-R$ method, while 

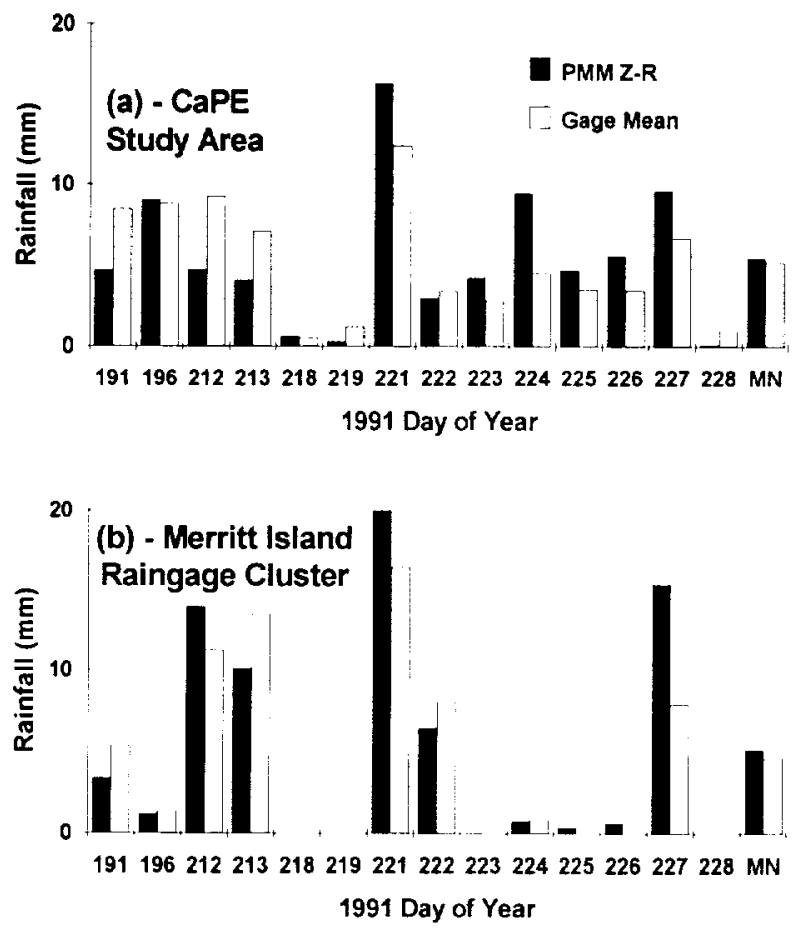

FIG. 11. (a) Daily rainfall estimates for 14 ditys and the 14-day mean rainfall (indicated by MN) for the CaPte study area derived from the gridded rain gange fieks and from the WSI composite radar images using the PMM-based $Z, R$ relationship. (b) Same as (a) except for the Merritt Istand rain gatuge cluster area.

correlations are nearly equal. The reduction of rmse using the PMM relationship is not due solely to the smaller biases; in fact, if the rmse values for both methods are adjusted for the respective biases, the comparison is not substantially altered. Correlations for both methods are slightly higher for the smaller region (greater than 0.9 ) than for the CaPE area (approximately 0.8 ), and are much higher than correlations found at gauge locations for 11-day total rainfall. The latter observation indicates that spatial averaging increases the correlation between radar and gauge rainfall.

This analysis of systematic and random errors shows that, in terms of bias and rmse of daily area-average rainfall estimates, the PMM is an improvement over the FACE relationship. This improvement is due partially to the fact that the PMM $Z-R$ relationship is tuned in a statistical sense to the local climatology and to the rain gauge and radar data used in its derivation. while the FACE relationship is not. However, identical reflectivity thresholds of $36.5 \mathrm{~dB} Z$ were applied to both relationships to avoid introducing additional bias into the FACE estimates by the composite radar data. The results indicate that a $Z-R$ relationship tuned to both the local climate and the radar datiset can produce better results than a power-law relationship developed from an independent dataset. In fact, due to limitations in radar calibration, screening methodologies, and variations in product generation, it is important in practice to apply an optimized $Z-R$ relationship.

\section{Summary}

One of the difficulties currently faced by investigators performing hydrologic studies at regional scales is the accurate estimation of precipitation. While rain gauges can provide accurate estimates at points, radar is important in providing the spatial distribution of rainfall. An important tool in estimating precipitation over areas greater than about $10^{5} \mathrm{~km}^{2}$ is radar imagery composited from multiple radars. In this paper we have discussed the utility of composite radar data in estimating convective rainfall using a conventional $Z-R$ relationship as well as the probability matching method.

The FACE and PMM $Z-R$ relationships were applied to composite radar imagery and various temporally and spatially averaged precipitation amounts were obtained. Batsed on point comparisons between radar and rain gauge rainfall, neither approach shows skill in estimating hourly, daily, or I 1-day accumulations at the local scale. While estimates from the PMM are only slightly biased with respect to gange amounts. rmse values for these integration periods are quite high. Estimates using the FACE $Z-R$ with a reflectivity threshold have larger biases than do the PMM estimates, and have slightly larger rmse. Although calculated correlation coefficients for hourly and daily estimates were higher than those for the 11-day period. we believe that the hourly and daily correlations are misleading due to heteroscedastic data, a violation of the simple linear regression model. Based on these results, we conclude that application of neither FACE nor PMM technique is appropriate for the retrieval of point rainfall. at least at the timescales used in this study. Several factors may contribute to the poor results at the point scale. First, the spatial scales corresponding to gauge and radar rainfall estimates are quite different. even at close

TAHH: 4. Statistics for area-average daily rainfall estimates using FACE and PMM $7, \ldots$ relitionships for CaPE study area and Merritt Island cluster areat. Given are gauge and radar means, radar-gauge correlations. and the square root of the mean-square error (rmse). FACE estimates are based on a $36.5-\mathrm{dB} Z$ threshold.

\begin{tabular}{lcccc}
\hline \hline & $\begin{array}{c}\text { Gauge } \\
\text { mean } \\
(\text { mum }\end{array}$ & $\begin{array}{c}\text { Radar } \\
\text { mean } \\
(\mathrm{mm})\end{array}$ & $\begin{array}{c}\text { Radar-gatge } \\
\text { correlation }\end{array}$ & $\begin{array}{c}\text { rmse } \\
(\mathrm{mm})\end{array}$ \\
\hline CaPE study area & & & & \\
FACE & 5.19 & 6.26 & 0.80 & 3.18 \\
PMM & 5.19 & 5.43 & 0.78 & 2.71 \\
Merritt Island clunter & & & & \\
FACE & 4.62 & 6.13 & 0.91 & 3.88 \\
PMM & 4.62 & 5.15 & 0.93 & 2.60 \\
\hline
\end{tabular}


range. At longer distances, this disparity is exaggerated, as the radar beam volume is large and high above the surface, so that effective reflectivity may be weakly correlated with surface precipitation. Second, the geolocation of radar pixels and timing of radar and gauge data are not precise enough to give good correlations between effective reflectivity and surface precipitation, especially considering the weak spatial correlation associated with the Florida summertime convective environment. Finally, rain gauges provide continuous measurements, while composite radar data provide snapshots at 15-min intervals. Radar rain rates must then be integrated across time to produce hourly and daily precipitation, introducing another source of error.

For daily precipitation integrated over the study area, correlations using both $Z-R$ relationships (approximately 0.8 for the CaPE study area and 0.9 for the smaller region ) are much higher than those for point comparisons. Using the FACE $Z-R$, rmse for daily rainfall over the study area is about $3.2 \mathrm{~mm}$, or $61 \%$ of the mean gauge-estimated rainfall. For the PMM, rmse is lower at $2.7 \mathrm{~mm}$, or $52 \%$ of the mean.

Precipitation estimates based on the FACE $Z-R$ relation were found to have large positive biases with respect to rain gauge observations. Mean 14-day precipitation estimates for the CaPE study area and the smaller Merritt Island area are approximately $90 \%$ and $110 \%$ higher than the corresponding amounts from the gauge network. These errors are due in part to radar beam spreading. which results in an enlargement of precipitation areas in the composite radar data. Biases of this magnitude are unacceptable for most applications, including agricultural guidance, flood warning, and surface and atmospheric water budget analyses. Much better results were obtained by applying a 36.5 $\mathrm{dBZ}$ threshold to rainfall retrievals using the FACE $Z$ $R$. This minimum value was determined by the PMM as that reflectivity necessary to equate the proportional space/time rainfall coverage as measured by radar to that reported by rain gauges. When the threshold is used, biases in the FACE rainfall estimates are reduced to $21 \%$ and $33 \%$ for the large and small areas, respectively. PMM-based 14-day precipitation estimates for the CaPE study area and Merritt Island show only small biases of $5 \%$ and $11 \%$, respectively, with respect to gauge totals. Thus, for this limited test case, the PMM technique is a significant improvement over the FACE $Z-R$ relation in terms of precipitation estimates averaged over the time and space domains examined here We conclude that it is important to apply a $Z-R$ relationship that is matched to local conditions and to the radar dataset.

Based on our analysis using data from central Florida. we conclude that there exist minimum spatial and temporal scales for which application of the PMM using composite reflectivity imagery is appropriate, although precise identification of these scales requires further investigation. The day-to-day variability of area-average radar rainfall estimates is considerable, differing by a factor of 2 above or below gauge estimates; however, area-averaged 14-day precipitation estimates from the PMM have very small biases. Thus, it appears that the minimum temporal scale for application of the PMM is several days. With regard to spatial scale, rainfall estimates for daily and longer time periods averaged over the Merritt Island region (350 $\mathrm{km}^{2}$ ) were found to be essentially as accurate as those over the larger CaPE study area $\left(21000 \mathrm{~km}^{2}\right)$. Attempts to estimate local precipitation at rain gauge sites for integration periods ranging from $1 \mathrm{~h}$ to 14 days compared poorly with rain gauge measurements. These results imply that the minimum spatial scale for daily rainfall estimation is smaller than that of the Merritt Island region, but greater than pixel scale $\left(4 \mathrm{~km}^{2}\right)$.

The existence of minimum time and space scales represents the integrating effect of multiple rain events. The nature and location of deep convection in Florida is controlled to a considerable degree by the synopticscale wind flow, which varies on timescales of one to a few days. Therefore, a time period of several days is required in order to capture a range of synoptic conditions. Results for shorter periods or at point sites are dominated by individual rain events; the PMM is not designed to accurately estimate precipitation for individual convective cells. As temporal and spatial averaging increase, precipitation becomes the integrated result of multiple rain systems at various stages of development. This situation is more consistent with the assumptions of the PMM, and more accurate precipitation estimates are possible.

\section{Conclusions and implications for NEXRAD applications}

Three conclusions regarding the use of composite radar data for rainfall estimation may be drawn from these results. First, we have found that a $Z-R$ relationship derived for a single radar under a certain set of environmental conditions (in this case the FACE $Z-R$ relationship $Z=300 R^{1.4}$ ) is not appropriate for use with composite reflectivity, unless a reflectivity threshold is applied, due primarily to the compositing procedure and effects of beam spreading. These effects are especially troublesome when using composite imagery in which identification of the contributing radar is not retained. Second, application of the probability matching method gives improved area-average rainfall estimates for daily and longer time periods, as measured by smaller biases and lower rmse with respect to ground truth rain gauge averages. Finally, daily areaaverage precipitation estimates from radar, using either $Z-R$ relationship, show much better agreement with gauge-derived mean rainfall than do estimates for specific gauge locations.

These conclusions raise an important question: How well can precipitation on a regional or national scale be 
Planned WSR-88D Radar Network

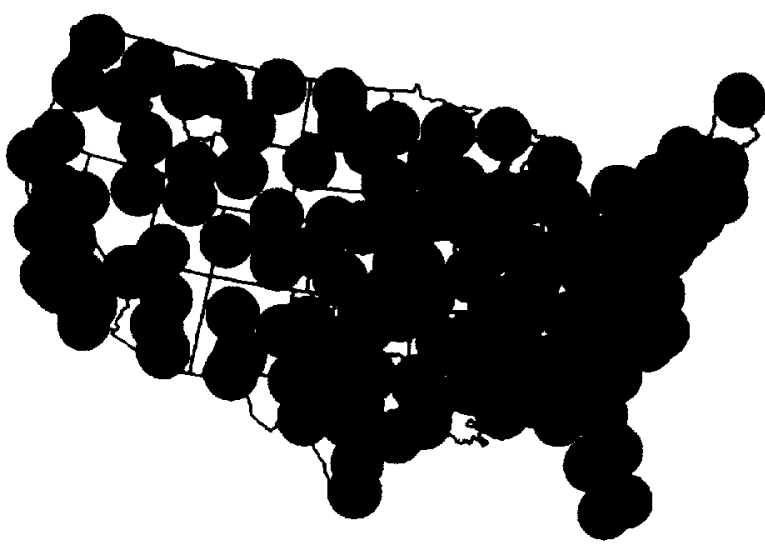

FIG. 12. Coverage over the continental United States by the planned WSR-88D radar network. Shading represents areas within a range of $180 \mathrm{~km}$ from the radar sites.

estimated using the NEXRAD system currently being deployed'? To illustrate the potential problems associated with range in this context, Fig. 12 shows $180-\mathrm{km}-$ range circles for each of the planned WSR-88D radar sites (Federal Meteorological Handbook 1991). This distance approximates the useful range of the radars for precipitation estimation. At $180-\mathrm{km}$ range, the WSR$88 \mathrm{D}$ beam center is at $3.5 \mathrm{~km}$ AGL. while the top of the beam volume is at $5.0 \mathrm{~km}$. At this distance, the aforementioned problems associated with frozen or mixed-phase hydrometeors, as well as beam geometry, begin to have serious impact on rainfall estimates. As shown in Fig. 12, coverage by the planned radar configuration is excellent in some regions, especially the Northeast and South Atlantic areas. However, there are several areas in excess of $180 \mathrm{~km}$ from the nearest radar, most notably in the West and the northern Plains, but also scattered throughout the South and Midwest. Furthermore, Fig. 12 represents an optimistic view of precipitation estimation from the NEXRAD network, as estimates at distances greater than about $150 \mathrm{~km}$ are suspect due to the large beamwidth at that range. Further examination of the magnitude and geographic distribution of errors in precipitation estimates obtained from the NEXRAD network is required.

Important issues regarding the use of composite radar for rainfall estimation include:

- What is the optimal $Z-R$ relationship, and how should it vary with region, season, and precipitation regime?

- What is the best way to account for range effects?

- What is the best compositing technique? Where there are coincident echoes from multiple radars, there are many ways in which to form composite images, such as mean reflectivity or maximum reflectivity. Alternatively, composite precipitation images may be constructed in which rain rate is averaged over individual radars.

The transferability of the PMM technique to different climate conditions and radar data, especially NEXRAD-derived products, needs to be examined. In testing the procedure under other climate conditions, it may be discovered that, due to regional differences, the PMM-based $Z-R$ relationship and the minimum space scales and timescales are different from those for Florida summertime conditions determined in this study. The $Z-R$ relation will depend strongly on the radar systems and the mix of convective and stratiform conditions, while space scales and timescales will be influenced by variations in the frequency of precipitation as well as the diversity of meteorological conditions.

Acknowledgments. Acquisition of the WSI NOWRAD radar data was made possible through James Dodge in support of the NASA WetNet Project. The authors wish to acknowledge the assistance of Steven Williams and Chuck Wade of the National Center for Atmospheric Research in providing the PAM data, and David Short and David Makofski of Goddard Space Flight Center for supplying rain gauge data from the KSC/TRMM and Upper St. John's Water Management District networks. Tom Renkevens of the University of Oklahoma and Joni Brooks of Columbia (TN) State Community College performed invaluable data processing and quality control tasks. The authors also thank Brian Motta of the WetNet Project for helpful information regarding the composite radar data and for reviewing the manuscript, and David Legates of the University of Oklahoma for providing computer programs for gridding and contouring rainfields. This research was supported by NASA Contracts NAS837140 and SUB93-216 and NASA Grant NAG8-922. Reference herein to any specific commercial products, process, or service by trade name, trademark, manufacturer, or otherwise, does not constitute or imply its endorsement. recommendation, or favoring by the United States Government or USRA.

\section{REFERENCES}

Afiti, A. A., and S. P. Aren, 1972: Statistical Analswis: A Computer Oriented Apprencth. Academic Press, $366 \mathrm{pp}$.

Atlas, D., D. Rosenfelt, and D. Short. 1990a: The estimation of convective raintall by area integrals. Part 1 : The theoretical and empirical basis. $J$. (ieophys. Res., 95, 2153-2160.

,.-., and D. B. Wolff, 1990h: Climatologically tuned reflectivity-rain rate relations and links to area time integrals. J. Appl. Metern. 29, $1120-11.35$.

-,- , and ....-. 1993: C'-band attenuation by tropical rainlall in Darwin. Australia. using climatologically tuned $Z_{r}-R$ relations. I. Appl. Meteer. 32, 426-430.

Battan. 1. J., 1973: Radar Observatom of the Atmosphere. University of Chicago Press, $324 \mathrm{pp}$.

Bringi, V. N. and A. Hendry. 1990): Techmology of polarization diversity radars for metcorology. Radar in Moteonology, D. Alas. Ed. Amer Meteor. Soc, $153-190$. 
Calheiros, R. V., and I. I. Zawadzki, 1987: Reflectivity rain-rate relationships for radar hydrology in Brazil. J. Climate Appl. Meteor., 26, $118-132$.

Doneaud, A. A., S. I. Niscov, D. L. Prignitz, and P. L. Smith. 1984: The area-time integral as an indicator for convective rainfall volumes. J. Climate Appl. Meteor, 23, 555-561.

Duchon, C. E.. T. M. Renkevens, and W. L. Crosson, 1995: Estimation of daily area-average rainfall during the CaPE experiment in central Florida. J. Appl. Meteror. 34, 2704-2714.

Federal Meteorological Handbook No. 11 (Interim Version One), 1991: Doppler Radar Meterorological Observations. Part A: System concepts, responsibilities, and procedures. FCM-HIIA1991, Office of the Federal Coordinator for Meteorological Services and Supporting Research, Rockville, MD, $58 \mathrm{pp}$.

Frank. N., P. L. Moore, and G. E. Fisher, 1967: Summer shower distribution over the Florida peninsula as deduced from digital radar. J. Appl. Meteor., 6, 309-316.

Gagin, A., D. Rosenfeld, and R. E. Lopez. 1985: The relationship between height and precipitation characteristics of summertime convective cells in south Florida. J. Atmess. Sci., 42, 84-94.

Hudlow, M. D. R. E. Arkell, V. L. Patterson, P. Pythowany, R. Richards, and S. G. Geotis, 1979: Calibration and interpretation of the GATE C-bund radars. NOAA Tech. Rep. EDIS 31, U.S. Department of Commerce, Washington, DC, $98 \mathrm{pp}$.

Leese, J. A., 1993: Implementation Plan for the GEWEX ContinentalScale International Project (GCIP). Data Collection and Operational Model Upgrade, 1GPO Publication Series, Vol. 1, 153 pp.

Lopez. R. E., D. Atlas, D. Rosenfeld, J. Thomas, D. O. Blanchard, and R. L. Holle, 1989: Estimation of rainfall using radar echo area time integral. I. Appl. Meteor., 28, 1162-1175.
Rosenfeld, D., D. Allas, and D. Short, 1990: The estimation of con vective rainfall by area integrals. Part 2: The height-area rainfall threshold (HART) method. I. Geophys. Res.. 95, $2161-$ 2176.

- D. Wolff, and E. Amitai, 1992: Beamwidth effects on $Z-R$ relations and area-integrated rainfall. $J . A / p l$. Metem., 31, $454-464$.

— D. Wolff, and D. Atlas, 1993: General probability-matched relations between radar reflectivity and rain rate. 1 . Appl. Meteor. 32, 50-72.

$\ldots$, and E. Amitai, 1994: The window probability matching method for rainfall measurements with radar. $J$. Appl. Meteor. 33, $682-693$.

Shepard, D., 1968: A two-dimensional interpolation function for irregularly-spaced data. Proc. ACM National Conf., 517-524.

- 1984: Computer mapping: The SYMAP interpolation algorithm. Spatial Statistics and Models, G. L. Gaile and C. J. Willmott, Eds., D. Reidel, 133-145.

Simpson, J., R. F. Adler, and G. R. North, 1988: A proposed Tropical Rainfall Measuring Mission (TRMM) satellite, Bull. Amer. Meterr. Soc. 69, 278-295.

Williams, S. F., K. Caesar, and K. Southwick, 1992: Convection and Precipitation/Electrification Experiment operations summary and data inventory. NCAR, Boulder, CO, $425 \mathrm{pp}$.

Willmott, C. J., and D. R. Legates, 1991: Rising estimates of terrestrial and global precipitation. Climate Res., 1, 179-186.

Woodley, W. L., A. R. Olsen, A. Herndon, and V. Wiggert, 1975: Comparison of gage and radar methods of convective rain measurement. J. Appl. Meteor., 14, 909-928.

Zawadzki, I. I., 1975: On radar-raingage comparison. J. Appl. Me' teor. 14, 1430-1436. 
